\title{
Determination of the prevalence of hypertension and factors associated with blood pressure among hospitalised elderly in Hospital Serdang, Selangor, Malaysia
}

\author{
Siti Nurhaliza Hashidi ${ }^{1}$, Noraida Omar $^{1,2^{*}}$ \& Siti Nur 'Asyura Adznam,2 \\ ${ }^{1}$ Department of Dietetics, Faculty of Medicine and Health Sciences, Universiti Putra \\ Malaysia, Selangor, Malaysia; ${ }^{2}$ Malaysian Research Institute on Ageing (MyAgeing), \\ Universiti Putra Malaysia, Selangor, Malaysia.
}

\begin{abstract}
Introduction: Increasing trends of hypertension has been recognised as a common disease among the elderly. This study aimed to determine the prevalence of hypertension and factors associated with blood pressure among hospitalised elderly. Methods: This was a cross-sectional study involving 124 patients in Hospital Serdang, Selangor, Malaysia. Data on socio-demography, medical background, anthropometry, blood biochemistry and lifestyle were collected through face-to-face interviews and medical records. Dietary intake was obtained through two days of food history. Malnutrition risks and stress level were determined using the Mini Nutritional Assessment Short-Form (MNA-SF) and the Geriatric Depression Scale (GDS). Results: There were $59.7 \%$ males and $40.3 \%$ females with mean age of $66.81 \pm 5.35$ years. Majority were found to have hypertension $(72.6 \%)$. Approximately $38.7 \%$ had normal body mass index (BMI). Most of them reported insufficient dietary intakes except for trans fats, sodium, and caffeine. Nearly $62.1 \%$ were engaged with physical activity, $23.4 \%$ were smoking, and $4.8 \%$ were taking alcohol. Approximately $66.1 \%$ and $86.3 \%$ were classified as having normal nutritional status and normal stress levels. In this study, the prevalence of hypertension among elderly patients warded in Hospital Serdang, Selangor was $72.6 \%$ and factors such as length of stay, number of co-morbidities, number of medications, having co-morbidities of hypertension, dyslipidaemia and diabetes mellitus, polypharmacy, height, BMI, fibre, polyunsaturated fat, dietary cholesterol, caffeine, and duration of physical activity were found to be associated with blood pressure. Conclusion: The present study found that majority of patients $(72.6 \%)$ had hypertension. Future studies regarding factors associated with blood pressure are recommended.
\end{abstract}

Keywords: Hypertension, blood pressure, elderly

\section{INTRODUCTION}

Both developed and developing countries are experiencing a phenomenon called "the greying of the planet" due to the reported significant number of people living to an advanced old age in this recent history (Jacob, 2016). According to the United Nations (UN), Malaysia is expected to increase two-fold of its elderly population, individuals aged 60

\footnotetext{
*Corresponding author: Noraida Omar

Department of Dietetics, Faculty of Medicine and Health Sciences, Universiti Putra Malaysia,

Selangor, Malaysia

Tel: (6)(03)97692463; Fax: (6)(03)89426769; E-mail: noraidaomar@upm.edu.my

doi: https://doi.org/10.31246/mjn-2020-0086
} 
years and above; from $7 \%$ to $15 \%$ in 2030 and further to $22 \%$ in 2050 (Abeykoon et al., 2017).

Based on the Clinical Practice Guidelines for Management of Hypertension (MSH, 2018), hypertension is defined as a persistent elevation in systolic blood pressure (BP) of 140 $\mathrm{mmHg}$ or greater and/or diastolic BP of $90 \mathrm{mmHg}$ or greater, with a minimum of twice measurements taken on two different occasions. Previous literature has reviewed the status of the prevalence of hypertension in six Southeast Asian countries consisting of Malaysia $(43.5 \%)$, Indonesia $(47.0 \%)$, Vietnam (25.1\%), Thailand (one of four adults), Philippines (22.3\%) and Singapore (23.5\%) (Oliva, 2019). The growing trends of hypertension among the elderly have been recognised in most Southeast Asian countries with the prevalence peaking among the age group of 65-69 years old at $74.0 \%$ and $53.4 \%$ in Malaysia and Singapore, respectively. Data by the National Health and Morbidity Survey (2019) in Malaysia also reported a rise in $\mathrm{BP}$ with increasing age as $81.7 \%$ of those aged 75 years old and above were found with the highest prevalence of hypertension.

Statistics from the Ministry of Health found high BP as the leading cause of mortality in Malaysia. Enhancement of lifestyle modification, which consists of modifiable factors, such as weight management, regular physical activity, smoking cessation, stress reduction, reduction of alcohol intake, and incorporation of heart-healthy diets, such as Dietary Approaches to Stop Hypertension (DASH) diet, manifests to be the first line of treatments in reducing the prevalence of hypertension (Whelton et al., 2018). Preventive care using nonpharmacologic lifestyle interventions should be encouraged as adjunctive therapy for managing high blood pressure among the elderly in order to reduce the length of hospitalisation, higher tendency of being exposed to infections, and number of treatments received (Oliveros et al., 2020). Moreover, hypertension as a "silent killer" not only results in asymptomatic mortality, but also deteriorates the quality of life for older people.

The cases of hypertension, especially among hospitalised elderly, have become an enormous concern among all health care professional teams working for an efficient management. Despite this, insignificant attention has been placed on the prevalence and associated factors of hypertension among hospitalised patients in the elderly age group of 60 years and above. Most research had been conducted among the general population or in community settings. This study was conducted with the purpose of improving the future health of the elderly in Malaysia. As such, this study aimed to contribute to existing literature by investigating the prevalence of hypertension in hospital settings, as well as factors associated with blood pressure.

\section{MATERIALS AND METHODS}

\section{Participants}

This was a cross-sectional study conducted at Hospital Serdang, Selangor, Malaysia. Purposive sampling was selected as the sampling design of this study. The appropriate sample size calculated based on the chosen correlation coefficient $(r)$ by Lin et al. (2019) was 113, and after adjusting for $10 \%$ of non-response rate, the minimum sample size needed in this study was 124 subjects. A total of 124 hospitalised elderly were recruited for this study (response rate of 100\%). The inclusion criteria included Malaysian citizen, and aged 60 years and above. This study excluded subjects with psychiatric illnesses, Alzheimer's disease, and those 
critically ill who needed to be ventilated or sedated, which might interrupt or delay the process of collecting data during the interview.

\section{Materials}

A self-administered questionnaire was developed to assess the sociodemographic characteristics of patients. Medical background and biochemical data were determined through hospital systems or bed-head tickets. Data for anthropometric measurements were obtained through medical records or interview sessions. If anthropometric data cannot be acquired through medical records or interview sessions, a physical examination was conducted with two readings recorded for every measurement.

Dietary intake was obtained through two days of food history on home diet consisting of one day weekday and one day weekend. Home diet was chosen as this type of diet is more accurate to review the trends of food intake among patients. Food intake was recorded using household measurements to assist precision in estimating patients' intakes. The Malaysian Food Composition Database (MyFCD) was referred for the analysis of dietary intakes. The findings were then analysed by using the Nutritionist Pro (Axxya Systems, USA) software.

Mini Nutritional Assessment Short Form (MNA-SF) was used as an adopted questionnaire to assess the risk of malnutrition among patients. It comprises of seven items with a sensitivity of $98 \%$, specificity of $100 \%$, and diagnostic accuracy of $99 \%$ for predicting undernutrition (Villalon, Laporte \& Carrier, 2011). Items 1 to 5 were determined through face-to-face interview, while items 6 and 7 were determined either through the hospital system or physical examination.
A semi-structured questionnaire was also used to evaluate the lifestyle of hospitalised elderly that consisted of physical activity, smoking status, and alcohol consumption. The findings were compared with standard recommendations from the Medical Nutrition Therapy (MNT) of Hypertension and Clinical Practice Guidelines (CPG) for Hypertension (MSH, 2018).

Stress level was assessed with an adapted questionnaire from the Geriatric Depression Scale (GDS) short form. This questionnaire consists of 15 close-ended questions, which is user-friendly for both healthy and physically ill subjects as it takes only about 5-7 minutes to complete, with $92 \%$ sensitivity and $89 \%$ specificity evaluated against diagnostic criteria among older populations (Greenberg, 2012).

Patients were classified as having hypertension based on self-report of having hypertension with medical diagnosis from doctors or medical officers and/or currently on treatments or taking any antihypertensive drugs. The BP taken on the day of the interview was further classified based on CPG for Hypertension (MSH, 2018).

\section{Procedure}

Data collection was conducted for three months from January to March 2020. Ethical approval was obtained from the MREC (Medical Research and Ethics Committee) (Project reference number: NMRR-18-3027-44602). Following ethical approval, an approval letter was obtained from the heads of department of the selected wards, which were surgical, medical, orthopaedic, urology, cardiology, and cardiothoracic. The content of the interview was explained to patients and informed consent was obtained before data collection. Patients were interviewed face-to-face with the use of a bilingual questionnaire 
that consisted of socio-demographic characteristics, medical background, anthropometric measurements, biochemical data, dietary intake, malnutrition risk, lifestyle, and stress level. The findings were analysed using IBM Statistics Version 22. The associations between categorical variables were determined by using Chi-Square Test, while the correlations between continuous variables were done by using Pearson's Product Moment Correlation Test with statistical significance level set at $p<0.05$.

\section{RESULTS}

The present study determined the prevalence of hypertension and the associations between socio-demographic characteristics, medical background, anthropometric measurements, biochemical data, dietary intake, malnutrition risks, lifestyle, and stress level with both systolic and diastolic BP.

Participants were $59.7 \%$ males and $40.3 \%$ females with mean age of $66.8 \pm 5.4$ years. Approximately $50.8 \%$ of the patients were Malays. Most received secondary education $(43.6 \%)$ and had a total monthly household income of $<$ RM1000 (59.7\%). More than half were married $(79.9 \%)$ and resided in urban areas (76.6\%) (Table 1).

Based on Table 2, majority of patients $(72.6 \%)$ had hypertension. Approximately $68.5 \%$ were classified as polypharmacy. Mean body mass index (BMI) was $25.2 \pm 5.3 \mathrm{~kg} / \mathrm{m}^{2}$, with $38.7 \%$ having normal BMI, followed by overweight (30.6\%), and underweight $(12.1 \%)$. Majority of the patients were presented with normal readings for most biochemical data, but approximately half of them were found with an abnormal level of fasting blood glucose (58.1\%) and creatinine level (50.8\%). Majority of them reported insufficient dietary intakes except for trans fat, sodium, and caffeine. For lifestyle, most of them $(62.1 \%)$ were engaged in physical activity, while approximately $23.4 \%$ and $4.8 \%$ were reported to be smoking and taking alcohol. The mean MNA-SF score was $12.1 \pm 2.4$, with $66.1 \%$ classified as having normal nutritional status. In the assessment for stress level, the mean score of GDS was $2.19 \pm 1.72$, with majority of the patients classified as having normal stress levels (86.3\%) and only $13.7 \%$ with mild depression.

The prevalence of hypertension among hospitalised elderly in Hospital Serdang, Selangor, Malaysia was $72.6 \%$, with mean systolic BP of $133.2 \pm 16.5$ $\mathrm{mmHg}$ and mean diastolic BP of 74.5 \pm 9.6 $\mathrm{mmHg}$, as illustrated in Table 3. Based on BP taken on the day of the interview, $27.4 \%$ had isolated systolic hypertension (ISH), followed by at risk of hypertension (22.6\%), normal BP (21.8\%), and optimal BP $(20.2 \%)$. Few patients had stage 1 $(5.6 \%)$ and stage $2(2.4 \%)$ hypertension.

Referring to Table 4, this study demonstrated no significant associations between age with BP of the patients $(p>0.05)$. Length of stay, number of comorbidities, and number of medications were found to be significantly associated with BP $(p<0.05)$. There was a significant positive correlation between height and BMI with systolic BP $(p<0.05)$. This study revealed that fibre, polyunsaturated fat (PUFA), dietary cholesterol, and caffeine were associated with BP $(p<0.05)$. The duration of physical activity was associated with systolic BP $(p<0.05)$.

As shown in Table 5, chi-square test was conducted for socio-demographic characteristics and no significant associations were found between sex, ethnicity, education level, marital status, monthly household income, and living area with BP. Other than that, there was also no significant association found between medical background and BP, 
Table 1. Socio-demographic characteristics of hospitalised elderly $(N=124)$

\begin{tabular}{|c|c|c|c|}
\hline Characteristics & $\begin{array}{l}\text { Total } \\
n(\%)\end{array}$ & $\begin{array}{l}\text { Male } \\
n(\%)\end{array}$ & $\begin{array}{c}\text { Female } \\
n(\%)\end{array}$ \\
\hline \multicolumn{4}{|l|}{ Sex } \\
\hline Male & $74(59.7)$ & - & - \\
\hline Female & $50(40.3)$ & - & - \\
\hline \multicolumn{4}{|l|}{ Ethnicity } \\
\hline Malay & $63(50.8)$ & $39(31.5)$ & $24(19.4)$ \\
\hline Chinese & $28(22.6)$ & $14(11.3)$ & $14(11.3)$ \\
\hline Indian & $31(25.0)$ & $20(16.1)$ & $11(8.9)$ \\
\hline Mixed race & $2(1.6)$ & $1(0.8)$ & $1(0.8)$ \\
\hline \multicolumn{4}{|l|}{ Marital Status } \\
\hline Single & $3(2.4)$ & $3(2.4)$ & $0(0.0)$ \\
\hline Married & 99 (79.9) & $68(54.8)$ & $31(25.0)$ \\
\hline Widow/Widower & $22(17.7)$ & $3(2.4)$ & 19 (15.3) \\
\hline \multicolumn{4}{|l|}{ Education level } \\
\hline No formal education & $13(10.5)$ & $5(4.0)$ & $8(6.5)$ \\
\hline Primary education & $38(30.6)$ & $18(14.5)$ & $20(16.1)$ \\
\hline Secondary education & $54(43.6)$ & $37(29.8)$ & $17(13.7)$ \\
\hline STPM/Foundation & $4(3.2)$ & $4(3.2)$ & $0(0.0)$ \\
\hline Diploma/Bachelor/Master & $15(12.1)$ & $10(8.1)$ & $5(4.0)$ \\
\hline \multicolumn{4}{|l|}{ Monthly household income } \\
\hline$<$ RM500 & $32(25.8)$ & $15(12.1)$ & $17(13.7)$ \\
\hline RM500-RM1000 & $42(33.9)$ & $26(21.0)$ & 16 (12.9) \\
\hline RM1001-RM1500 & $10(8.1)$ & 7 (5.7) & $3(2.4)$ \\
\hline RM1501-RM2000 & $14(11.3)$ & $12(9.7)$ & $2(1.6)$ \\
\hline > RM2000 & $26(21.0)$ & $14(11.3)$ & $12(9.7)$ \\
\hline \multicolumn{4}{|l|}{ Living area } \\
\hline Urban & $95(76.6)$ & 42 (33.9) & 38 (30.6) \\
\hline Rural & $29(23.4)$ & $32(25.8)$ & $12(9.7)$ \\
\hline
\end{tabular}

except for co-morbidities of hypertension, dyslipidaemia and diabetes mellitus, and also polypharmacy.

\section{DISCUSSION}

Based on the definition of BP used in the present study, the prevalence of hypertension among hospitalised elderly in Hospital Serdang, Selangor, Malaysia was $72.6 \%$, which was found to be two to three times higher compared to a previous study (45.6\%) conducted among non-institutionalised Malaysian elderly (Eshkoor et al., 2016). However, only $58.0 \%$ of hospitalised elderly in Hospital Serdang were reported with hypertension after being referred for BP assessment on the day of the interview. The prevalence might have varied as patients were more likely to receive proper monitoring and treatments during hospitalisation. Upon assessment, approximately $27.4 \%$ had ISH, a type of hypertension commonly found among older individuals. Based on the World Health Organization (WHO) ISH criterion of $>140 / 90 \mathrm{mmHg}$, the prevalence of ISH ranges from 5-35\% for different countries in Asia and varies from one community to another according to economic development.

A previous literature that reviewed the status of hypertension in six Southeast Asian countries comprising of 
Table 2. Medical background, anthropometric and biochemical data, dietary intake, malnutrition risk, lifestyle, and stress level of hospitalised elderly $(N=124)$

\begin{tabular}{|c|c|}
\hline Characteristics & Mean $\pm S D$ \\
\hline \multicolumn{2}{|l|}{ Medical background } \\
\hline Length of stay (days) & $3.93 \pm 4.09$ \\
\hline Co-morbidities & $2.93 \pm 1.54$ \\
\hline Number of medications & $8.12 \pm 6.21$ \\
\hline \multicolumn{2}{|l|}{ Anthropometric } \\
\hline Weight (kg) & $66.5 \pm 13.9$ \\
\hline Height (cm) & $162.3 \pm 8.8$ \\
\hline BMI $\left(\mathrm{kg} / \mathrm{m}^{2}\right)$ & $25.3 \pm 5.3$ \\
\hline \multicolumn{2}{|l|}{ Biochemical } \\
\hline LDL-C (mmol/L) & $2.55 \pm 0.87$ \\
\hline HDL-C (mmol/L) & $1.15 \pm 0.31$ \\
\hline $\mathrm{TG}(\mathrm{mmol} / \mathrm{L})$ & $1.42 \pm 0.63$ \\
\hline Total cholesterol (mmol/L) & $4.10 \pm 1.52$ \\
\hline Fasting blood glucose (mmol/L) & $6.99 \pm 4.22$ \\
\hline Potassium $(\mathrm{mmol} / \mathrm{L})$ & $4.21 \pm 0.67$ \\
\hline Creatinine (mmol/L) & $161.7 \pm 174.1$ \\
\hline \multicolumn{2}{|l|}{ Dietary intake } \\
\hline Energy (kcal) & $1575 \pm 567$ \\
\hline Carbohydrate (g) & $272.4 \pm 320.1$ \\
\hline Fibre $(g)$ & $6.06 \pm 3.99$ \\
\hline Protein (g) & $52.8 \pm 22.5$ \\
\hline Fat $(\mathrm{g})$ & $43.1 \pm 24.2$ \\
\hline Saturated fat $(g)$ & $7.91 \pm 6.78$ \\
\hline Polyunsaturated fat (PUFA) (g) & $6.40 \pm 7.15$ \\
\hline Monounsaturated fat (MUFA) (g) & $7.28 \pm 7.73$ \\
\hline Trans fat $(\mathrm{g})$ & $0.00 \pm 0.00$ \\
\hline Dietary cholesterol (mg) & $97.4 \pm 126.1$ \\
\hline Sodium (mg) & $1988 \pm 1106$ \\
\hline Caffeine (cups) & $1.07 \pm 1.07$ \\
\hline Fluid (cups) & $4.26 \pm 2.02$ \\
\hline \multicolumn{2}{|l|}{ Malnutrition risks } \\
\hline Total score MNA-SF & $12.1 \pm 2.4$ \\
\hline \multicolumn{2}{|l|}{ Lifestyle } \\
\hline Physical activity (min/week) & $185.9 \pm 347.3$ \\
\hline Smoking (pieces/day) & $3.77 \pm 8.55$ \\
\hline Alcohol (unit/day) & $0.06 \pm 0.32$ \\
\hline \multicolumn{2}{|l|}{ Stress level } \\
\hline Total score GDS & $2.19 \pm 1.72$ \\
\hline
\end{tabular}

Malaysia, Indonesia, Vietnam, Thailand, Philippines and Singapore consistently presented advanced age as a significant contributing factor for elevated BP (Oliva, 2019). As most of the patients in the present study were males $(59.7 \%)$, therefore sex, education level, and living areas were also discussed as possible factors associated with hypertension. However, another study with similar findings found no significant association between age, sex differences, and 
Table 3. Prevalence of hypertension among hospitalised elderly $(N=124)$

\begin{tabular}{|c|c|c|c|c|}
\hline \multirow{2}{*}{ Classification } & \multirow{2}{*}{$M e a n \pm S D$} & Total & Male & Female \\
\hline & & \multicolumn{3}{|c|}{$n(\%)$} \\
\hline Systolic BP (mmHg) & $133.2 \pm 16.5$ & & & \\
\hline Diastolic BP (mmHg) & $74.5 \pm 9.59$ & & & \\
\hline Hypertension & & $90(72.6)$ & $53(42.7)$ & $37(29.8)$ \\
\hline \multicolumn{5}{|l|}{ Normal blood pressure } \\
\hline $\begin{array}{l}\text { Optimal (<120mmHg, } \\
<80 \mathrm{mmHg})\end{array}$ & & $25(20.2)$ & $19(15.3)$ & $6(4.8)$ \\
\hline $\begin{array}{l}\text { Normal (120-129mmHg, } \\
\text { 80-84mmHg) }\end{array}$ & & $27(21.8)$ & $15(12.1)$ & $12(9.7)$ \\
\hline \multicolumn{5}{|l|}{ At risk \& high blood pressure } \\
\hline $\begin{array}{l}\text { At risk (130-139mmHg, } \\
\text { 85-89mmHg) }\end{array}$ & & $28(22.6)$ & $17(13.7)$ & $11(8.9)$ \\
\hline $\begin{array}{l}\text { Stage } 1(140-159 \mathrm{mmHg} \\
90-99 \mathrm{mmHg})\end{array}$ & & $7(5.6)$ & $5(4.0)$ & $2(1.6)$ \\
\hline $\begin{array}{l}\text { Stage } 2(160-179 \mathrm{mmHg} \\
100-109 \mathrm{mmHg})\end{array}$ & & $3(2.4)$ & $1(0.8)$ & $2(1.6)$ \\
\hline $\begin{array}{l}\text { Stage } 3(\geq 180 \mathrm{mmHg} \\
\geq 110 \mathrm{mmHg})\end{array}$ & & $0(0.0)$ & $0(0.0)$ & $0(0.0)$ \\
\hline $\begin{array}{l}\text { Isolated Systolic } \\
\text { Hypertension }(\geq 140 \mathrm{mmHg} \text {, } \\
<90 \mathrm{mmHg})\end{array}$ & & $34(27.4)$ & $17(13.7)$ & $17(13.7)$ \\
\hline
\end{tabular}

ethnicity with poor BP control (Cheong et al., 2015). Diverse studies revealed that variations in the suggested factors associated with $\mathrm{BP}$ are reasonably due to differences in study design, social and cultural differences, dietary, and lifestyle factors.

Hypertension has been reported as one of the most frequent morbidities with an additional of at least one other diagnosis upon hospital admissions in a cohort study conducted within one Canadian hospital (Specogna et al., 2017). This study also further discussed the presence of co-morbidities that were found to be associated with an increase in hospital stay and a higher cost of hospital care. A study conducted in Malaysia found a significant association between the presence of co-morbidities and the number of medications used, with $51.7 \%$ having poor BP control (Cheong et al., 2015). Other than that, there was also a significant relationship between three or more antihypertensive agents with poor BP control. An analysis by the National Health and Nutrition Examination Survey (NHANES) suggested that although polypharmacy helped with the improvement in BP among elderly with three or more BP medications, yet it is also reported as a significant factor for the lack of medication adherence that possibly caused alteration in BP (Egan et al., 2014). Therefore, productive efforts for complex management of blood pressure following the increasing number of older people in Malaysia should be emphasised in minimising the negative impacts on the elderly, as well as on our country's health care status and economy.

A higher prevalence of hypertension was reported among the elderly with high BMI (Eshkoor et al., 2016; Seow et al., 2015). The urbanisation of Malaysia as a developing country has exposed people towards a more sedentary and 
Table 4. Correlations between socio-demographic, medical background, anthropometric, biochemical, dietary intake, malnutrition risk, lifestyle, and stress level with blood pressure among hospitalised elderly $(N=124)$

\begin{tabular}{|c|c|c|c|c|}
\hline \multirow{2}{*}{ Variables } & \multicolumn{2}{|c|}{ Systolic BP } & \multicolumn{2}{|c|}{ Diastolic BP } \\
\hline & $r$ & $p$ & $r$ & $p$ \\
\hline \multicolumn{5}{|l|}{ Socio-demographic } \\
\hline Age & 0.07 & 0.45 & 0.02 & 0.84 \\
\hline \multicolumn{5}{|l|}{ Medical background } \\
\hline Length of stay (days) & -0.16 & 0.07 & -0.20 & $0.03^{*}$ \\
\hline Co-morbidities & 0.17 & $0.05^{*}$ & -0.04 & 0.66 \\
\hline Number of medications & 0.20 & $0.03^{*}$ & -0.07 & 0.42 \\
\hline \multicolumn{5}{|l|}{ Anthropometric } \\
\hline Weight (kg) & 0.15 & 0.10 & 0.05 & 0.62 \\
\hline Height (m) & -0.21 & $0.02 *$ & -0.06 & 0.53 \\
\hline $\mathrm{BMI}\left(\mathrm{kg} / \mathrm{m}^{2}\right)$ & 0.25 & $0.01^{*}$ & 0.06 & 0.53 \\
\hline \multicolumn{5}{|l|}{ Biochemical } \\
\hline LDL-C (mmol/L) & 0.09 & 0.33 & 0.10 & 0.29 \\
\hline HDL-C (mmol/L) & 0.03 & 0.77 & -0.10 & 0.26 \\
\hline $\mathrm{TG}(\mathrm{mmol} / \mathrm{L})$ & 0.04 & 0.70 & 0.11 & 0.21 \\
\hline Total cholesterol (mmol/L) & 0.03 & 0.75 & 0.09 & 0.34 \\
\hline Fasting blood glucose (mmol/L) & 0.17 & 0.07 & 0.14 & 0.13 \\
\hline Potassium (mmol/L) & 0.00 & 0.97 & -0.05 & 0.57 \\
\hline Creatinine (mmol/L) & 0.16 & 0.08 & 0.01 & 0.89 \\
\hline \multicolumn{5}{|l|}{ Dietary intake } \\
\hline Energy (kcal) & -0.08 & 0.41 & 0.00 & 0.94 \\
\hline Carbohydrate (g) & -0.06 & 0.52 & -010 & 0.29 \\
\hline Fibre (g) & 0.04 & 0.63 & 0.20 & $0.03 *$ \\
\hline Protein (g) & -0.15 & 0.09 & -0.05 & 0.59 \\
\hline Fat $(g)$ & 0.03 & 0.72 & 0.03 & 0.75 \\
\hline Saturated fat $(g)$ & 0.03 & 0.72 & 0.05 & 0.61 \\
\hline Polyunsaturated fat (PUFA) (g) & 0.21 & $0.03 *$ & 0.14 & 0.11 \\
\hline Monounsaturated fat (MUFA) (g) & 0.15 & 0.10 & 0.11 & 0.22 \\
\hline Dietary cholesterol (mg) & -0.02 & $0.03^{*}$ & -0.20 & $0.03^{*}$ \\
\hline Sodium (mg) & 0.07 & 0.43 & 0.01 & 0.90 \\
\hline Caffeine (cups) & 0.22 & $0.01^{*}$ & 0.13 & 0.15 \\
\hline Fluid (cups) & -0.06 & 0.50 & 0.00 & 0.95 \\
\hline \multicolumn{5}{|l|}{ Malnutrition risk } \\
\hline Total score MNA-SF & -0.05 & 0.58 & -0.06 & 0.51 \\
\hline \multicolumn{5}{|l|}{ Lifestyle } \\
\hline Physical activity (min/week) & -0.21 & $0.02 *$ & -0.10 & 0.26 \\
\hline Smoking (pieces/day) & -0.13 & 0.14 & -0.05 & 0.58 \\
\hline Alcohol (unit/day) & 0.04 & 0.68 & 0.07 & 0.43 \\
\hline \multicolumn{5}{|l|}{ Stress level } \\
\hline Total score GDS & 0.08 & 0.37 & 0.03 & 0.78 \\
\hline
\end{tabular}

*Significant at $p<0.05$ 
Table 5. Associations between socio-demographic characteristics and medical background with blood pressure among hospitalised elderly $(n=124)$

\begin{tabular}{|c|c|c|c|c|}
\hline Variables & $\begin{array}{c}\text { Normal BP } \\
n(\%)\end{array}$ & $\begin{array}{c}\text { At-risk \& high } \\
B P \\
n(\%)\end{array}$ & $x^{2}$ & $p$ \\
\hline \multicolumn{5}{|c|}{ Socio-demographic characteristics } \\
\hline Sex & & & 1.21 & 0.27 \\
\hline Male & $34(27.4)$ & $40(32.3)$ & & \\
\hline Female & $18(14.5)$ & $32(25.8)$ & & \\
\hline Ethnicity & & & 0.27 & 0.61 \\
\hline Malay & $25(20.2)$ & 38 (30.6) & & \\
\hline Non-Malay & $27(21.8)$ & $34(27.4)$ & & \\
\hline Education level & & & 2.29 & 0.13 \\
\hline With education & $44(35.5)$ & $67(54.0)$ & & \\
\hline No formal education & $8(6.5)$ & $5(4.0)$ & & \\
\hline Marital Status & & & 0.05 & 0.83 \\
\hline Married & $42(33.9)$ & $57(46.0)$ & & \\
\hline Not married & $10(8.1)$ & $15(12.1)$ & & \\
\hline Monthly household income & & & 0.57 & 0.45 \\
\hline$\leq \mathrm{RM} 1000$ & $29(23.4)$ & $45(36.3)$ & & \\
\hline >RM1001 & $23(18.5)$ & $27(21.8)$ & & \\
\hline Living area & & & 0.00 & 0.95 \\
\hline Urban & $40(32.3)$ & $55(44.4)$ & & \\
\hline Rural & $12(9.7)$ & $17(13.7)$ & & \\
\hline \multicolumn{5}{|l|}{ Medical background } \\
\hline Referral to dietitian & $3(2.4)$ & $5(4.0)$ & 0.07 & 0.79 \\
\hline \multicolumn{5}{|l|}{ Comorbidities } \\
\hline Hypertension & $31(25.0)$ & $59(47.6)$ & 7.56 & $0.01^{*}$ \\
\hline Dyslipidaemia & $15(12.1)$ & $34(27.4)$ & 4.27 & $0.04 *$ \\
\hline Diabetes mellitus & $25(20.2)$ & $53(42.7)$ & 8.44 & $0.00^{*}$ \\
\hline Ischemic heart disease & $12(9.7)$ & $28(22.6)$ & 3.46 & 0.06 \\
\hline Others & $26(21.0)$ & $36(29.0)$ & 0.00 & 1.00 \\
\hline \multicolumn{5}{|l|}{ Family history } \\
\hline Hypertension & $15(12.1)$ & $22(17.7)$ & 0.04 & 0.84 \\
\hline Others & $27(21.8)$ & $48(38.8)$ & 0.16 & 0.69 \\
\hline Polypharmacy & $28(22.6)$ & $57(46.0)$ & 8.98 & $0.00^{*}$ \\
\hline
\end{tabular}

${ }^{*}$ Significant at $p<0.05$

unhealthy lifestyle, which further increases the rate of BMI exceeding the normal range (Oliva, 2019). It has also been observed that the prevalence of hypertension increased along with the rising number of those who were overweight or obese. On the other hand, another study suggested that higher BMI was able to reduce the risk of developing hypertension among older adults as the main cause leading to hypertension was the gradual increase in arterial stiffness rather than obesity itself (Pikilidou et al., 2013).

Although no significant relationship between biochemical data and blood pressure was found, past literature suggested for the monitoring of biochemical data due to its possibility to cause any other health-related events. 
Hypertensive elderly, particularly those with dyslipidaemia, require appropriate treatments to achieve normal BP by controlling associated risk factors including lipid profile. This can be done by having low-density lipoprotein cholesterol (LDL-C) within normal range through discard of endogenous and exogenous cholesterol, reduce triglycerides (TG), and improve highdensity lipoprotein cholesterol (HDL-C) level (Gómez, 2012). In the present study, more than half were presented with an abnormal level of fasting blood glucose (FBG) and creatinine. Several studies found significant associations between FBG with systolic and diastolic BP, yet there is a need for extensive research in a longitudinal study to observe the relationship between hypertension and hyperglycaemia due to a lack in conclusive evidence (Yan et al., 2016). Moreover, a study suggested high level of creatinine as a beneficial biomarker for the screening of renal status among hypertensive patients that is necessary for appropriate treatments (Pandya, Nagrajappa \& Ravi, 2016).

Consumption of foods high in polyunsaturated fat, dietary fibre, and dietary cholesterol were presented with a positive relationship either with systolic BP alone or with both systolic and diastolic BP (Sakurai et al., 2011). Although majority of the patients (75.8\%) in this study had at least two cups of coffee or tea or less, which represented an adequate recommended intake of caffeine, yet caffeine consumption was found to be significantly associated with uncontrolled blood pressure, as supported by previous literature (Lopez-Garcia et al., 2016). Consistent findings suggested that variations in dietary intake such as the DASH eating pattern within recommended amounts helped with the optimal control of blood pressure, especially among older individuals (Tyson et al., 2012). In the present study, most of the patients complained of no appetite, food was hard to chew or swallow, food was not appealing, and poor meal-related situations that might have influenced the insufficient intakes of most of their dietary nutrient components (Yahya et al., 2020). The difference in findings on nutrient components can be due to several reasons such as poor food choices and difficulty in getting the exact information for their daily consumption, as well as variations in lifestyle, as discussed in previous literature (Shahrin et al., 2019a).

A past study conducted in Turkey that focused on non-hospital settings found a significant association between hypertension and malnutrition due to various factors such as health status, taste perception, and decline in physical ability, thus making older people $70 \%$ more vulnerable of being malnourished (Basibüyük et al., 2019). This study also discussed the vulnerability of elderly towards diseases, which has resulted in poor nutritional status. However, fewer studies were available to determine the relationship between blood pressure and the use of MNA among older individuals.

Some studies demonstrated a sedentary lifestyle or no physical activity as a significant contributor to the risk of developing an age-related disease such as hypertension (Pilleron et al., 2017) due to its beneficial role in improving muscle strength and flexibility among the geriatric population (Yahya et al., 2019a). However, a study among the elderly in Singapore found that physically active elderly were more likely to perceive their health status to be in a good condition, which then reduced their awareness about the risk of developing hypertension (Seow et al., 2015). Despite the fact that smoking cessation improves BP, cigarette smoking 
was found to be prevalent among hypertensive patients in Southeast Asia (Oliva, 2019). Optimal control of BP was observed among current smokers even though they were presented with a lower rate of awareness about their health conditions (Seow et al., 2015). In the present study, only $4.8 \%$ reported alcohol intake, with a consumption of $<2$ drinks per day, appropriate with the recommended intake established by CPG for Hypertension (MSH, 2018).

Increasing events of chronic illness expose older individuals with the risk of developing stress and reduce their health-related quality of life (Yahya et al., 2019b; Yahya et al., 2019c; Shahrin et al., 2019b; Shahrin et al., 2019c). Based on statistics by the WHO, it was estimated that about $15 \%$ of older people aged 60 years and above were suffering from mental disorders. Although no significant association was found between stress level and $\mathrm{BP}$, changes that occur throughout the ageing process including the presence of chronic illness, such as hypertension, has been reported with a $5-37 \%$ range for depression among elderly in the primary care settings (Jacob, 2016). Thus, good management and social support during hospitalisation can be contributing factors for the improvement of mental health status as well as blood pressure control in the elderly.

\section{CONCLUSION}

The findings of this study presented the prevalence of hypertension as $72.6 \%$ among hospitalised elderly patients in Hospital Serdang, Selangor. Factors such as length of stay, number of comorbidities, number of medications, having co-morbidities of hypertension, dyslipidaemia and diabetes mellitus, polypharmacy, height, BMI, fibre intake, polyunsaturated fat, dietary cholesterol and caffeine intakes, and duration of physical activity were found to be associated with $\mathrm{BP}$ among these patients.

Nevertheless, variables such as age, sex, ethnicity, education level, marital status, monthly household income, living area, biochemical data, malnutrition risk, smoking status, alcohol intake, and stress level were not found to be associated with BP. Therefore, regular monitoring of BP among hospitalised elderly is crucial to reduce the risk of mortality and morbidity among the geriatric population. The present study provides a better understanding of the factors associated with BP for appropriate preventive measures and intervention to improve the well-being of older people. Further research on the factors associated with BP, especially in hospital settings in Malaysia, is recommended.

\section{Acknowledgments}

The authors wish to thank the Director General of Health Malaysia for his permission to publish this article. The authors also would like to extend their gratitude to hospitalised elderly and Ministry of Health Malaysia staffs involved at Hospital Serdang, Selangor for their cooperation.

\section{Authors' contributions}

$\mathrm{SNH}$, researcher, devised and conducted the study, data analysis and interpretation, prepared the draft of the manuscript; NO, principal investigator, assisted in study and result interpretation, reviewed the manuscript; SNAA, provided critical input and reviewed the manuscript.

\section{Conflict of interest}

The authors declared no conflict of interest.

\section{References}

Abeykoon DA, Murat MN, Rocas MG, Naraval DA \& Camilo (2017). Ageing Thailand, Malaysia, Indonesia and Cambodia: Demographic transition, policy and programmatic responses. International Council on Management of Population Programmes (ICOMP), Ampang, Selangor. 
Basibüyük GÖ, Ayremlou P, Aeidlou SNS, Çinar Z, Ay F, Bektas Y \& Vitályos GÁ (2019). Evaluation of malnutrition among elderly people living in nursing homes by Mini Nutritional Assessment Short Form (MNA-SF) in Turkey. Maedica $14(1): 38-44$.

Cheong AT, Sazlina SG, Tong SF, Azah AS \& Salmiah S (2015). Poor blood pressure control and its associated factors among older people with hypertension: A cross-sectional study in six public primary care clinics in Malaysia. Malays Fam Physician 10(1):19-25.

Egan BM, Li J, Shatat IF, Fuller JM \& Sinopoli A (2014). Closing the gap in hypertension control between younger and older adults: National Health and Nutrition Examination Survey (NHANES) 1988 to 2010. Circulation 129(20):2052-2061. https://doi.org/10.1161/ CIRCULATIONAHA.113.007699

Eshkoor S, Hamid T, Shahar S, Ng C \& Mun C (2016). Factors Affecting Hypertension among the Malaysian Elderly. J Cardiovasc Dev Dis 3(1):8. https://doi.org/10.3390/jcdd3010008

Gómez PC (2012). Lipid disorders in elderly hypertensive patients. Int $J$ Hypertens 2012:684515 https://doi. org/10.1155/2012/684515

Greenberg SA (2012). The geriatric depression scale (GDS). Best Practices in Nursing Care to Older Adults, 4(1):1-2.

Jacob R (2016). Aging and current trends in Malaysia. International Journal of Social Work and Human Services Practice 4(3):57-61.

Lin YA, Chen YJ, Tsao YC, Yeh WC, Li WC, Tzeng IS \& Chen JY (2019). Relationship between obesity indices and hypertension among middle-aged and elderly populations in Taiwan: a community-based, cross-sectional study. BMJ Open 9(10):e031660. https://doi. org/10.1136/bmjopen-2019-031660

Lopez-Garcia E, Orozco-Arbeláez E, Leon-Muñoz LM, Guallar-Castillon P, Graciani A, Banegas JR \& Rodríguez-Artalejo F (2016). Habitual coffee consumption and 24-h blood pressure control in older adults with hypertension. Clin Nutr 35(6):1457-1463. https://doi. org/10.1016/j.clnu.2016.03.021

MSH (2018). Clinical Practice Guidelines (CPG) Management of Hypertension (5th edition). Malaysian Society of Hypertension. Ministry of Health Malaysia.
Oliva RV (2019). A Review on the status of hypertension in six Southeast Asian countries. Hypertension $J$ 5(2). Doi: 10.15713/ins. johtn.0151

Oliveros E, Patel H, Kyung S, Fugar S, Goldberg A, Madan N \& Williams KA (2020). Hypertension in older adults: Assessment, management, and challenges. Clin Cardiol 43(2):99-107. https:/ / doi.org/10.1002/clc.23303

Pandya D, Nagrajappa AK, \& Ravi KS (2016). Assessment and correlation of urea and creatinine levels in saliva and serum of patients with chronic kidney disease, diabetes and hypertension- A research study. J Clin Diagn Res 10(10):ZC58-ZC62.

Pikilidou MI, Scuteri A, Morrell C \& Lakatta EG (2013). The burden of obesity on blood pressure is reduced in older persons: The SardiNIA study. Obesity 21(1):E10-E13. https://doi. org/10.1002/oby. 20010

Pilleron S, Aboyans V, Mbelesso, NdambaBandzouzi, Desormais, Lacroix, Preux, Guerchet, Desormais, Desport \& Jésus (2017). Prevalence, awareness, treatment, and control of hypertension in older people in Central Africa: the EPIDEMCA study. $J \mathrm{Am}$ Soc Hypertens 11(7):449-460. https://doi. org/10.1016/j.jash.2017.04.013

Sakurai M, Stamler J, Miura K, Brown IJ, Nakagawa H, Elliott P, Ueshima H, Chan Q, Tzoulaki I, Dyer AR \& Okayama A (2011). Relationship of dietary cholesterol to blood pressure: The INTERMAP study. $J$ Hypertens 29(2):222-228. https://doi.org/10.1097/ HJH.Ob013e32834069a5

Seow LSE, Subramaniam M, Abdin E, Vaingankar JA, \& Chong SA (2015). Hypertension and its associated risks among Singapore elderly residential population. $J$ Clin Gerontol Geriatr 6(4):125-132. https://doi.org/10.1016/j. jcgg.2015.05.002

Shahrin FI, Omar N, Daud ZA \& Zakaria NF (2019a). Factors associated with food choices among elderly: A scoping review. Mal J Nutr 25(2): 185 .

Shahrin FI, Yu LZ, Omar N, Zakaria NF \& Daud ZA (2019b). Association of socio-demographic characteristics, nutritional status, risk of malnutrition and depression with quality of life among elderly haemodialysis patients. Mal $\mathrm{J}$ Nutr 25(1):1-11. 
Shahrin FI, Omar N, Daud ZA, \& Zakaria NF (2019c). Assessment of health-related quality of life in the elderly on maintenance hemodialysis. Malaysian J Med Health Sci 15(SP1):90-95.

Specogna AV, Turin TC, Patten SB \& Hill MD (2017). Hospital treatment costs and length of stay associated with hypertension and multimorbidity after hemorrhagic stroke. BMC Neurology 17(1):1-8. https://doi.org/10.1186/ s12883-017-0930-2

Tyson CC, Nwankwo C, Lin PH \& Svetkey LP (2012). The dietary approaches to stop hypertension (dash) eating pattern in special populations. Curr Hypertens Rep. NIH Public Access. https:/ /doi.org/ 10.1007/s11906-012-0296-1

Villalon L, Laporte M \& Carrier N (2011). Nutrition screening for seniors in health care facilities: A survey of health professionals. Can $J$ Diet Pract Res 72(4):162-169. https://doi. org/10.3148/72.4.2011.162

Whelton PK, Carey RM, Aronow WS, Casey $\mathrm{DE}$, Collins $\mathrm{KJ}$, Himmelfarb $\mathrm{CD}$, DePalma SM, Gidding S, Jamerson KA, Jones DW, MacLaughlin EJ. (2018). 2017 ACC/AHA/ AAPA / ABC / ACPM / AGS / APhA/ASH / ASPC/ NMA/PCNA Guideline for the prevention, detection, evaluation, and management of high blood pressure in adults: a report of the American College of Cardiology/ American Heart Association Task Force on Clinical Practice Guidelines. J Am Coll Cardiol 71(19):e127-e248. https://doi.org/10.1016/j. jacc. 2017.11 .006
Yahya NF, Omar N, Yusof BN, Adznam SN \& Daut UN (2019a). Functional status by fat-free mass index among elderly with chronic obstructive pulmonary disease in respiratory clinics, Malaysia. Ann Nutr Metabol 75:82.

Yahya NF, Omar N, Adznam SN, Daut UN \& Yusof BN (2019b). Health-related quality of life of elderly with chronic obstructive pulmonary disease from selected government institutions. Mal J Nutr 25(1):27-36.

Yahya NF, Omar N, Adznam SN, Daut UN \& Yusof BN (2019c). A systematic review on factors associated with health-related quality of life among chronic obstructive pulmonary disease patients. Malaysian J Med Health Sci 15(SP1):61-68.

Yahya NF, Omar N, Daut UN, Adznam SN \& Yusof BN (2020). Dietary Nutrient Intake and Mealrelated Situations among Elderly Outpatients with Chronic Obstructive Pulmonary Disease from Respiratory Clinics, Malaysia. Malaysian J Med Health Sci 16(SUPP6):170-177.

Yan Q, Sun D, Li X, Chen G, Zheng Q, Li L, Gu C \& Feng B (2016). Association of blood glucose level and hypertension in Elderly Chinese Subjects: A community based study. BMC Endocr Disord 16:40. https://doi.org/10.1186/s12902-0160119-5 